DOI: $10.17805 /$ zpu.2015.4.3

\title{
Этнокультурный фактор персональной модернизации *
}

\author{
4. К. ЛАМАЖАА \\ (МОСКОВСКИЙ ГУМАНИТАРНЫЙ УНИВЕРСИТЕТ)
}

В статье обобщаются теоретические представления о персональной модернизации, обосновывается актуальность анализа этнокультурного фактора данного микроуровня модернизации. Под персональной модернизацией еще в 1970-х годах понимались не только функционально запрашиваемые качества человека (узкая профессионализация, экономический интерес, эффективность, планирование времени), но и ряд принципиальных социокультурных изменений - развитие рациональности, инновативности, формирования в себе субъекта творческой деятельности, способности быть персонально ответственным, привыкать к разнообразию взглядов, обретать личное достоинство, партикуляризм и оптимизм (А. Инкельс, Д. Смит). Тем не менее в научной литературе сохранялось разделение представлений о человеческом факторе модернизации - в зависимости от той стороны модернизации, которую авторы предпочитали считать наиважнейшей (экономическая, политическая и пр.).

В трактовке автора статьи (в развитие идей В. Г. Федотовой, М. Вебера) этнокультурный фактор определяет такие важнейшие характеристики инновационной личности, как персональность и внутренняя дистанция. Принятие человеком новых ценностей и установок, позволяющих ему реализовывать свой творческий потенциал, добиваться экономического благосостояния в условиях определенной социальной конкуренции одновременно сопровождается приверженностью своей социокультурной идентичности, базовым ценностям своей этнической культуры. Именно действие этого фактора способно определять облик модернизации как на персональном уровне, так и на общественном - не позволяя трансформирующемуся обществу менять свои и социокультурные основания, полностью вестернизироваться.

Ключевые слова: модернизация; персональная модернизация; этническая культура; этнокультурный фактор; человеческий потенциал

\section{ВВЕАЕНИЕ}

$\mathbf{R}$ российской социальной, гуманитарной науке тема персональной модернизации модернизации человека - стала обсуждаться во второй половины 2000-х годов, причем пробивалась эта идея со значительными трудностями, особенно в философских кругах (см.: Федотова, 2007: 163). Несмотря на то что теории модернизации, пришедшие к нам с Запада, стали востребованы и активно обсуждались применительно к общественным процессам, человеческий аспект модернизации не воспринимался, поскольку, по мнению противников такого подхода, он упрощает человека до определенных функциональных черт (там же). Ряд авторов все же выступили в научной литературе за эту тему, и в их числе: В. Г. Федотова, В. П. Веряскина, В. Б. Власова, Н. С. Петренко и др., практически все - представители Института философии РАН. Мы также писали об этом, предлагая рассматривать этнокультурный фактор персональной модернизации.

В данной статье мы обобщим имеющиеся работы по этой теме и конкретизируем наши предложения.

* Подготовлено при поддержке РГНФ (проект «Философский анализ проектов конструирования человека: идеалы и технологии», грант № 15-23-01008а(м)).

The article was written with support from the Russian Foundation for the Humanities (Project title «Philosophical analysis of projects of constructing man: ideals and technologies», Grant No. 15-23-01008a(м)). 
ПЕРСОНАИЬНАЯ МОАЕРНИЗАЦИЯ

Прежде всего остановимся на определении персональной модернизации. Западные теоретики модернизации - осовременивания общества (А. Инкельс, А. Смит, $\Lambda$. Аиаманд и др.) еще с 1970-х годов рассуждали о человеческом основании общественных процессов. В частности, А. Инкельс и А. Смит под персональной модернизацией в работе 1974 г. понимали не только функционально запрашиваемые качества человека - узкую профессионализацию, экономический интерес, эффективность, планирование времени, но и ряд принципиальных социокультурных изменений развитие рациональности, инновативности, формирования в себе субъекта творческой деятельности, способности быть персонально ответственным, привыкать к разнообразию взглядов, обретать личное достоинство, партикуляризм и оптимизм (Inkeles, Smith, 1974: 15-35; Федотова, 2007: 163).

Тем не менее в научной литературе сохранялось определенное разделение представлений о человеческом факторе модернизации - в зависимости от той стороны модернизации, которую авторы предпочитали считать наиважнейшей, и основывалось это на общем понимании факторов социальных процессов. Например, известны истоки представлений об экономическом человеке как двигателе прогресса (А. Смит, K. Маркс и др.), что было развито позднее в работах Аж. Бьюкенена, Г. Таллока, М. Фридмана, В. С. Автономова, И. В. Розмаинского и Ар. (Бьюкенен, Таллок, 1997; Фридман, 1991; Автономов, 1998; Розмаинский, 2005). Как пишет В. Г. Федотова, развитие общества потребления привело к тому, что модель «экономического человека» была распространена посредством социальных технологий на поведение тех, кто не был причастен к производству иначе, чем через потребление, но должен был проявить в нем чрезвычайную устремленность к максимуму удовлетворений и минимуму издержек, сформированную посредством символизации престижных и модных товаров (Федотова, 2007а: 166).

О политическом человеке писали политологи, разрабатывавшие тему политической культуры, которая, по их убеждению, определяет особенности политической жизни, политических процессов в каждом обществе (Х. Файер, Г. Алмонд, С. Верба, А. $\Lambda$ ипсет, $\Lambda$. Пай, Р. Роуз, М. Крозье и др.). Соответственно, человек модернизированный с этой точки зрения ориентирован на либерально-демократическую модель политической культуры, основанную на обеспечении политических прав и свобод гражданина, регламентации жизнедеятельности общества исключительно через правовое регулирование. В этой модели основными ценностями признаны: права человека, свобода, плюрализм в идеологии, политике, экономике, демократия, правопорядок, неприкосновенность частной жизни и частной собственности, приоритетность общественного мнения, гражданское общество, экология и др. Изменение в системе ценностей и моделях поведения людей ряд авторов полагают основным фактором как политического развития, так и модернизации в целом: К. Аойч, А. Инкельс, Р. Инглхарт и дp. (Deutsch, 1974; Inkeles, Smith, 1974; Инглхарт, Вельцель, 2011). Исследователи политической культуры, безусловно, рассматривали уже и в целом фактор культуры, определяющий особенности сознания и поведения человека.

Сегодня политэкономические теории капитализма преобразуются с учетом задач «новой экономики» и запросов на творческую личность. Западным ученым и организациям (Всемирному банку, Организации экономического сотрудничества и развития) принадлежит заслуга в разработке таких понятий, как социальный, человеческий, культурный и символический капитал. $\mathrm{OOH}$ использует более абстрактные характери- 
стики: социальный, человеческий, культурный и символический потенциал. На концепцию внеэкономического капитала работают понятия «интеллектуальный капитал», «творческий капитал». Философы говорят также об экономическом, социальном, человеческом, культурном, символическом, интеллектуальном творческом потенциалах (Федотова, 2007: 168).

Условием эффективного функционирования современного человека стали считать взаимное влияние институционального, организационного и личностного уровня. В этой связи ряд авторов, в том числе и упоминавшиеся выше, попытались сформулировать модель «современного человека». Одно из таких исследований было проведено под эгидой Гарвардского проекта по социальным и культурным аспектам развития еще в 1970-х годах (под руководством А. Инкельса), когда изучалось население шести развивающихся стран (Аргентина, Чили, Индия, Израиль, Нигерия и Пакистан). В результате были выделены черты современной личности:

1) открытость әкспериментам, инновациям и изменениям;

2) готовность к плюрализму мнений и даже к одобрению этого плюрализма;

3) ориентация на настоящее и будущее, а не на прошлое, экономия времени, пунктуальность;

4) способность организовать свою жизнь так, чтобы преодолевать создаваемые ею препятствия;

5) планирование будущих действий для достижения предполагаемых целей;

6) вера в регулируемость и предсказуемость социальной жизни, позволяющая рассчитывать действия;

7) чувство справедливости распределения;

8) высокая ценность формального образования и обучения;

9) уважение достоинства других, включая тех, у кого более низкий статус или кто обладает меньшей властью.

В. Г. Федотова персональную модернизацию в своих работах тесно связывает с идеями М. Вебера. В ее трактовке веберовская концепция рассматривает две важнейшие характеристики личности, которые определяют ее как инновационную: персональность и внутренняя дистанция. «Персональность характеризует отношение человека к конечным смыслам. Это то, что поднимает индивида над рутиной повседневности, ее "растительной» основой. Твердая приверженность определенным нормам возвышает над обыденностью, не отнимая возможность жить в повседневном мире» (Федотова, 2007b: 23). «Внутренняя дистанция, в понимании Вебера, означает способность индивида отказаться от тех образцов поведения и ценностей, которые не соответствуют персональности, твердым принципам индивида (там же: 24). Основным же двигателем социальных изменений, в том числе модернизационных перемен, является противоречие между харизмой и рутинизацией. Харизматический лидер выступает как источник новых взглядов и верований. Затем следует фаза рутинизации, превращения необычных идей в рутину, факт повседневной жизни. Это осуществляется как путем систематизации верований интерпретаторами и распространения ее догматов среди населения, так и путем приспособления системы верований к интересам различных слоев (там же: 23). Этот процесс и был проанализирован М. Вебером на примере протестантизма, революционное значение которого состояло в революционном преобразовании части западного общества путем поддержания и выдвижения на роль культурного образца трудового аскетизма рядовых людей, совпадающего с идеей аскетизма протестантской секты как найденного ею пути к спасению (там же: 24-25). 
В. Б. Власова пишет, что в персональной модернизации уместно видеть не только и, может быть, не столько часть целого или слагаемое некой «суммарной» трансформации общественной жизни, сколько самостоятельное осуществление более или менее значимых внутренних преобразований ценностных ориентаций личности (Власова, 2006).

Н. С. Петренко связывает персональную модернизацию с изменением социокультурной модели индивида, приближением к идеалу современности на атомарном уровне, в котором одним из должных качеств человека является его интуиция, чутью на такую вещь, как современность, т. е. качество своевременности. Своевременность автор описывает как некоторое сложное соответствие течения личностного времени человека и внеположного ему объективного хода вещей, на фоне более или менее параллельного течения которого происходит (или не происходит, или должно произойти, ожидается) некое новое событие (Петренко, 2008).

Мы сформулируем определение персональной модернизачии как микроуровня модернизации (макроуровень - модернизация всего общества; мезоуровень - модернизация социальных групп), на котором происходит принятие человеком новых ценностей и установок, позволяющих ему реализовывать свой творческий потенциал, добиваться экономического благосостояния в условиях определенной социальной конкуренции, при этом сохраняя свою социокультурную идентичность, приверженность базовым ценностям. Распространенность персональной модернизации в развивающемся, модернизируемом - осовременивающемся - обществе становится условием успешности всей модернизации. Причем успешности не только в степени изменений, но и в степени сохранности социокультурных оснований общества.

\section{ЭТНОКУАБТУРНЫЙ ФАКТОР}

Значимость этнокультурного фактора, по нашему мнению, тесно связана со значением персональности как твердой приверженности определенным нормам (по В. Г. ФеАотовой). В некотором смысле это то же оливковое дерево, о котором писал Т. Фридман (Фридман, 2003). Однако, если основная идея американского журналиста заключалась в противопоставлении двух начал мировых социальных процессов - двигателя для процветания и развития, символизируемого «Иексусом», и желания сохранить идентичность и традиции, символизируемого оливковым деревом, то мы полагаем, что по крайней мере второй символ по своей сути сложнее и многозначнее.

С одной стороны, действительно, этническая культура, определяемая как совокупность форм человеческой деятельности, обретенных знаний, образов самопознания и символических обозначений окружающего мира, выступает в качестве структурообразующей основы этноса, обеспечивающей его целостность и способность к автономному устойчивому развитию (Бромлей, 1983: 44-57; Костина, 2009: Электронный ресурс). Соответственно, механизм сохранения целостности этнической культуры, осуществляемый в форме традиции, не позволит одномоментно перестроить общность на иной лад. Ценности своей культуры, признаваемые членами этнической общности, будут настолько прочны и будут определять характер социальных процессов, насколько они глубоко усвоены большинством в данной общности и насколько неизменными они оставались на протяжении длительного времени (безусловно, эволюционируя).

Но, с другой стороны, этнокультурная самобытность способна определять облик модернизации как на персональном уровне, так и на общественном - не позволяя трансформирующемуся обществу менять свои и социокультурные основания, пол- 
ностью вестернизироваться. Разумеется, процессы глобализации не могут не затрагивать культурные основания обществ, поскольку распространяются и в сфере массовой культуры, привлекая доступностью, универсальностью, условиями моды, космополитичностью (см.: Костина, 2006аb). Тем не менее ряд исследователей считают, что культурная глобализация проявляется как процесс двусторонний, в который существенный вклад вносят и незападные страны, активно противостоящие влиянию американской культуры и организующие циркуляцию тех смыслов и значений, которые продуцируются в собственных культурных границах, способствуя сплочению нации и поддержанию традиции. Подобное активное сопротивление нивелирующему влиянию североамериканской культуры, заключает А. В. Костина, проявляется не только в стремлении к интеграции и углублению культурного взаимодействия, но и в намеренном возрождении собственных этнокультурных оснований (Костина, 2006а: 129).

Однако воздействие этнической культуры на процесс общественной модернизации лишь номинально можно рассматривать с двух сторон. С позиции же социального реализма, с которой отечественные философы предлагают рассматривать проблему персональной модернизации (см.: Модернизация и глобализация ... , 2002: 172-173), соотношение уровней модернизации (персональной и общественной), а также этнокультурного фактора с модернизацией на всех ее уровнях - многосторонне. Развивая мысль теоретика социально-функционального подхода в социологии Т. Парсонса, авторы утверждают, что общественная система при изменении своей структуры сталкивается с инерцией индивидуального сознания, которое не может на когнитивном уровне осмыслить необходимость нововведений и новых ценностей, так как в большинстве случаев приверженность устоявшимся правилам была привита нормативным способом. Ценности этнической культуры, в числе которых и приверженность традициям, и коллективные ценности, прививаются человеку с детства, он их не осмысливает и принимает как должное. Тем не менее человек взрослеющий, развивающийся как личность, способен осознавать полезность, стратегическую цель принятия и иных ценностей, причем не меняя свою идентичность, принимая новые стратегии рационально. Задача общества, политика государства, ориентированного на модернизацию, состоит в создании соответствующих общественных институтов, которые должны обеспечивать быструю переориентацию индивидов на новые ценности и нормы посредством специально разработанных механизмов внушения. И поскольку тотальное отрицание старого будет иметь лишь разрушающий само общество эффект, государственная политика должна также быть направленной на поддержание тех общественных институтов, которые ориентируют на сохранность и развитие традиций.

В отношении российского общества часто высказываются неутешительные заключения об утрате значительного объема ценностных установок традиционной культуры, как этнической, так и общей советской, о механическом заимствовании западных клише и соответственно духовной деградации населения, в том числе молодой его части. Именно этот вакуум, по мнению многих исследователей, приводит к пробуксовке модернизационных подвижек: не позволяет не только «догнать и перегнать» Запад, но и сформулировать собственный эффективный путь развития. Однако, на наш взгляд, все это происходит на фоне непродуманной государственной политики, в том числе и в сфере индустрии массовых развлечений (телевидения, кино и пр.), которая стала каналом для вестернизации общества, и так ослабленного периодом тотальной либерализации 1990-х годов. 
Феномены персональной модернизации в современной России можно наблюдать в определенных условиях, которые во многом сложились как результат сочетания ряда обстоятельств, далеко не всегда являющихся результатом продуманной стратегии. Мы наблюдали, например, жизнь представителей этнической диаспоры в мегаполисе - этнических тувинцев, проживающих в Москве. И заключали, что приверженность к сохранившим во многом свою силу этническим корням не только не затрудняет модернизацию, но и в определенных обстоятельствах помогает ей, делает процессы более успешными (Ааргын-оол, 2006аb). Осознание уникальности своей этнической культуры наполняет существование человека особой персональностью и осознанием морального императива для отказа от чуждых образцов, т. е. помогает более эффективно осуществлять модернизацию с опорой на собственную традиционность. С одной стороны, большинство «новоселов»-тувинцев в Москве вынуждено подчиняться правилам нового места, меняя свое поведение и образ мышления. А с другой стороны, этнокультурная идентичность выполняет адаптивную функцию и представляет для них внутреннюю, духовную преграду от механического копирования иных культурных образцов поведения. Более того, члены диаспоры, в том числе молодежь, признаются в своем большом желании быть сопричастными к жизни своей республики: приносить какую-либо пользу в позитивных преобразованиях в ней, использовать накапливаемый столичный опыт для внедрения инновационных идей и проектов на малой Родине - Туве. К обстановке чужого окружения, новых правил, естественно, быстрее адаптируется молодежь. Она лучше и быстрее вписывается в современный ритм города. Молодым людям уже труднее дается обратная адаптация (реадаптация) в размеренном образе жизни на исторической родине, потому они часто стремятся продолжить учебу и (или) остаться работать вдалеке от нее. Численность диаспоры каждый год увеличивается, пополняясь, в том числе, за счет бывших студентов, выпускников учебных заведений. Человек в мегаполисе осовременивается, понимает себя как активного участника социальных изменений, в нем вырабатывается инновационное мышление и он начинает испытывать еще один дискомфорт от существенного разрыва в уровне развития - модернизации столичного мегаполиса и своего общества исхода, родительской культуры.

Выходцы из традиционных обществ, попадающие в активно модернизирующийся регион, вынуждены менять ориентир с одного на противоположный, с традиции на инновацию. Тем самым они переживают (не менее драматично, но по времени быстрее) индивидуальную модернизацию и в итоге «обгоняют» в своем личностном развитии свой исконный, «коренной» социум. Потому среди членов диаспоры отмечается большая критичность в отношении к социальным процессам на малой Родине, к деятельности своих бывших коллег, земляков. Что не мешает им испытывать ностальгию, верить в свое возвращение, а также в изменения к лучшему в жизни своей республики.

\section{ЗАКАЮЧЕНИЕ}

Аля России тема персональной модернизации и факторов ее развития и торможения, в том числе этнокультурного, имеет большое значение, поскольку культурная самобытность многонационального общества является ее отличительной особенностью. Эта основа представляет собой богатство (духовное, материальное) нации, а также определяет неоднородность социального развития в региональном разрезе, которое в итоге выражается в социально-экономических показателях, в особенно- 
стях политической жизни. Как подчеркивает В. П. Веряскина, персональную модернизацию необходимо сделать стратегическим приоритетом развития России, так как построение постиндустриального общества и инновационной экономики напрямую зависит от наличия человеческого капитала и эффективности развития человека, что определяется как расширение свободы выбора, и на этой основе - деятельности в различных сферах социальной жизни (Веряскина, 2013: 89). Поэтому мы утверждаем о необходимости дальнейшего анализа этнокультурного фактора модернизации, в частности исследований персональной модернизации в целом и учета этого в социальной практике.

\section{СПИСОК АИТЕРАТУРЫ}

Автономов, В. С. (1998) Модель человека в экономической науке. СПб. : Экономическая школа. 230 с.

Бромлей, Ю. В. (1983) Очерки теории этноса. М. : Наука. 413 с.

Бьюкенен, Аж., Таллок, Г. (1997) Расчет согласия. Аогические основания конституционной демократии // Бьюкенен Аж. Конституция экономической политики. Расчет согласия. Границы свободы. М. : Таурус Альфа. 560 с.

Веряскина, В. П. (2013) Персональная модернизация - стратегическая цель развития России и ее регионов / Такие разные России. Ч. І. Круглый стол журнала «Полис» и сектора социальной философии Института философии РАН / И. К. Пантин, В. Г. Федотова, М. Г. Алиев, В. П. Веряскина, Г. А. Хакимов, В. Б. Власова // Полис. № 2. С. 85-89.

Власова, В. Б. (2006) Соотношение персональной модернизации с социальными процессами // Знание. Понимание. Умение. № 4. С. 104-111.

Ааргын-оол, Ч. К. (2006а) Аиаспора в мегаполисе: традиции и современность (начало) // Знание. Понимание. Умение. № 2. С. 96-101.

Ааргын-оол, Ч. К. (2006b) Аиаспора в мегаполисе: традиции и современность (окончание) // Знание. Понимание. Умение. № 3. С. 109-115.

Инглхарт, Р., Вельцель, К. (2011) Модернизация, культурные изменения и демократия: Последовательность человеческого развития. М. : Новое издательство. 464 с.

Костина, А. В. (2006а) Национальная и этническая культура: соотношение в глобализирующемся мире (начало) // Знание. Понимание. Умение. № 3. С. 128-139.

Костина, А. В. (2006b) Национальная и этническая культура: соотношение в глобализирующемся мире (окончание) // Знание. Понимание. Умение. № 4. С. 165-172.

Костина, А. В. (2009) Этническая культура: специфика развития в современном мире [Электронный ресурс] // Новые исследования Тувы. № 1-2. С. 175-189. URL: http:// tuva.asia/journal/issue_1-2/118-ethnic-culture.html [архивировано в WebCite] (дата обращения: 12.09.2015).

Модернизация и глобализация : образы России в XXI веке (2002) / отв. ред. В. Г. Федотова. М. : ИФ РАН. 208 c.

Петренко, Н. С. (2008) Идея своевременности как часть контекста теорий персональной модернизации // Знание. Понимание. Умение. № 2. С. 136-142.

Розмаинский, И. В. (2005) «Посткейнсианская модель человека» и хозяйственное поведение россиян в 1990-е годы // Terra Economicus. Т. 3. № 1. С. 62-73.

Федотова, В. Г. (2007а) Человеческий капитал, персональная модернизация и проблема развития человека (начало) // Знание. Понимание. Умение. № 1. С. 163-169.

Федотова, В. Г. (2007b) Человеческий капитал, персональная модернизация и проблема развития человека (окончание) // Знание. Понимание. Умение. № 2. С. 21-27.

Фридман, М. (1991) Четыре шага к свободе // Общественные науки и современность. №3. C. $16-19$.

Фридман, Т. (2003) Lexus и олива. Понимая глобализацию. М. : ИГ «Весь». 448 с.

Deutsch, K. W. (1974) Politics and government: How people decide their fate. 2nd edn. Boston : Houghton Mifflin Company. 607 p. 
Inkeles, A., Smith, D. (1974) Becoming modern: Individual change in six developing countries. Cambridge, MA : Harvard University Press. 437 p.

Аата поступления: 12.09.2015 2.

\section{THE ETHNOCULTURAL FACTOR IN PERSONAL MODERNIZATION \\ CH. K. LAMAZHAA \\ (MOSCOW UNIVERSITY FOR THE HUMANITIES)}

The article sums up theoretical concepts of personal modernization and explains the relevance of analyzing the ethnocultural factor at this micro-level of modernization.

As early as in the 1970s personal modernization was understood as comprising not only the functionally required human features (narrow specialization, economic interest, efficiency, time management), but also a number of important sociocultural modifications, such as the development of rationality, innovation, shaping oneself as a creative individual, capable of accepting responsibility, tolerating the variety of views, and endowed with personal dignity, particularism and optimism (A. Inkeles, D. Smith). Nevertheless, researchers were still committed to shaping the human factor of modernization in accordance with whichever aspect of modernization - economic, political, or any other they chose to move to the forefront.

Building on the ideas advanced by Valentina Fedotova and Max Weber we believe that the ethnocultural factor determines the development of such crucial constituents of innovative man as personality and internal distance. Accepting new values and orientations which help people realize their creative capabilities and achieve economic well-being under pressure of social competition is, at the same time, accompanied by commitment to one's own sociocultural identity and the basic values of ethnic culture. It is this factor that determines the face of modernization both on the personal and social levels, preventing the transforming society from losing its sociocultural foundation and from complete Westernization.

Keywords: modernization; personal modernization; ethnic culture; ethnocultural factor; human capability

\section{REFERENCES}

Avtonomov, V. S. (1998) Model' cheloveka v ekonomicheskoi nauke [The model of man in economics]. St. Petersburg, Ekonomicheskaia shkola Publ. 230 p. (In Russ.).

Bromlei, Yu. V. (1983) Ocherki teorii etnosa [Essays on the theory of ethnos]. Moscow, Nauka Publ. 413 p. (In Russ.).

Buchanan, J. and Tullock, G. (1997) Raschet soglasiia. Logicheskie osnovaniia konstitutsionnoi demokratii [The calculus of consent: Logical foundations of constitutional democracy]. In: Buchanan, J. Konstitutsiia ekonomicheskoi politiki. Raschet soglasiia. Granitsy svobody [The constitution of economic policy. The calculus of consent. The limits of liberty]. Moscow, Taurus Al'fa Publ. 560 p. (In Russ.).

Veriaskina, V. P. (2013) Personal'naia modernizatsiia - strategicheskaia tsel' razvitiia Rossii i ee regionov [Personal modernization as a strategic objective for the development of Russia and its regions] / Takie raznye Rossii. Ch. I. Kruglyi stol zhurnala «Polis» i sektora sotsial'noi filosofii Instituta filosofii RAN [Widely different Russias. Pt. 1. A roundtable hosted by the Polis journal and the Department of Social Philosophy, Institute of Philosophy, RAS] / I. K. Pantin, V. G. Fedotova, M. G. Aliev, V. P. Veriaskina, G. A. Khakimov and V. B. Vlasova. Polis, no. 2, pp. 85-89. (In Russ.).

Vlasova, V. B. (2006) Sootnoshenie personal'noi modernizatsii s sotsial'nymi protsessami [A correlation between personal modernization and social processes]. Znanie. Ponimanie. Umenie, no. 4, pp. 104-111. (In Russ.).

Dargyn-ool, Ch. K. (2006a) Diaspora v megapolise: traditsii i sovremennost' (nachalo) [Diaspora in a megalopolis: Traditions and modernity (the beginning)]. Znanie. Ponimanie. Umenie, no. 2, pp. 96-101. (In Russ.). 
Dargyn-ool, Ch. K. (2006b) Diaspora v megapolise: traditsii i sovremennost' (okonchanie) [Diaspora in a megalopolis: Traditions and modernity (the ending)]. Znanie. Ponimanie. Umenie, no. 3, pp. 109-115. (In Russ.).

Inglehart, R. and Welzel, C. (2011) Modernizatsiia, kul'turnye izmeneniia $i$ demokratiia: Posledovatel' nost' chelovecheskogo razvitiia [Modernization, cultural change, and democracy: The human development sequence]. Moscow, Novoe izdatel'stvo Publ. 464 p. (In Russ.).

Kostina, A. V. (2006a) Natsional'naia i etnicheskaia kul'tura: sootnoshenie v globaliziruiushchemsia mire (nachalo) [National and ethnic culture: Their correlation in the globalizing world (the beginning)]. Znanie. Ponimanie. Umeni, no. 3, pp. 128-139. (In Russ.).

Kostina, A. V. (2006b) Natsional'naia i etnicheskaia kul'tura: sootnoshenie v globaliziruiushchemsia mire (okonchanie) [National and ethnic culture: Their correlation in the globalizing world (the ending)]. Znanie. Ponimanie. Umenie, no. 4, pp. 165-172. (In Russ.).

Kostina, A. V. (2009) Etnicheskaia kul'tura: spetsifika razvitiia v sovremennom mire [Ethnic culture: Particularities of development in the contemporary world]. Novye issledovaniia Tuvy, no. 1-2, pp. 175-189. URL: http://tuva.asia/journal/issue_1-2/118-ethnic-culture.html [archived in WebCite] (accessed 12.09.2015). (In Russ.).

Modernizatsiia i globalizatsiia : obrazy Rossii v XXI veke [Modernization and globalization: Images of Russia in the 21st century] (2002) / ed. by V. G. Fedotova. Moscow, Publ. House of the Institute of Philosophy, RAS. 208 p. (In Russ.).

Petrenko, N. S. (2008) Ideia svoevremennosti kak chast' konteksta teorii personal'noi modernizatsii [The idea of timeliness as a contextual element of personal modernization theory]. Znanie. Ponimanie. Umenie, no. 2, pp. 136-142. (In Russ.).

Rozmainskii, I. V. (2005) «Postkeinsianskaia model' cheloveka» i khoziaistvennoe povedenie rossiian v 1990-e gody [“The post-Keynesian model of man" and Russians' economic behavior in the 1990s]. Terra Economicus, vol. 3, no. 1, pp. 62-73. (In Russ.).

Fedotova, V. G. (2007a) Chelovecheskii kapital, personal'naia modernizatsiia i problema razvitiia cheloveka (nachalo) [Human capital, personal modernization and the problem of human development (the beginning)]. Znanie. Ponimanie. Umenie, no. 1, pp. 163-169. (In Russ.).

Fedotova, V. G. (2007b) Chelovecheskii kapital, personal'naia modernizatsiia i problema razvitiia cheloveka (okonchanie) [Human capital, personal modernization and the problem of human development (the ending)]. Znanie. Ponimanie. Umenie, no. 2, pp. 21-27. (In Russ.).

Friedman, M. (1991) Chetyre shaga k svobode [Four steps to freedom]. Obshchestvennye nauki i sovremennost', no. 3, pp.16-19. (In Russ.).

Friedman, T. (2003) Lexus i oliva. Ponimaia globalizatsiiu [The Lexus and the olive tree: Understanding globalization]. Moscow, Ves' Publ. Group. 448 p. (In Russ.).

Deutsch, K. W. (1974) Politics and government: How people decide their fate. 2nd edn. Boston, Houghton Mifflin Company. 607 p.

Inkeles, A. and Smith, D. (1974) Becoming modern: Individual change in six developing countries. Cambridge, MA, Harvard University Press. 437 p.

Submission date: 12.09.2015.

Аамажаа Чимиза Кудер-ооловна - доктор философских наук, заместитель директора Института фундаментальных и прикладных исследований Московского гуманитарного университета; академик Международной академии наук (Инсбрук, Австрия). Адрес: 111395, Россия, г. Москва, ул. Юности, д. 5, корп. 6. Тел.: +7 (499) 374-75-95. Эл. адрес: lamajaа@mail.ru

Lamazhaa Chimiza Kuder-oolovna, Doctor of Philosophy, Deputy Director, Institute of Fundamental and Applied Studies, Moscow University for the Humanities; Full Member, International Academy of Science (Innsbruck, Austria). Postal address: Bldg. 6, 5 Yunosti St., 111395 Moscow, Russian Federation. Tel.: +7 (499) 374-75-95. E-mail: lamajaa@mail.ru 